\title{
Comparison of Stresses for Circular and Rectangular Pre-stressing Plates in Post-Tensioned Anchorage Zone \\ ${ }^{* 1}$ Monika R. Jain, ${ }^{2}$ Rajendra N. Khapre \\ ${ }^{1,2}$ Shri Ramdeobaba College of Engineering and Management, Nagpur \\ Email: ${ }^{j}$ jainmr_3@rkned.edu, ${ }^{2}$ khaprern@rknec.edu
}

Received: 06th November 2019, Accepted: 20th November 2019, Published: 31st December 2019

\begin{abstract}
This paper presents the case study on 3-dimensional analysis of end block of rectangular post tensioned concrete beam. The end block of post tensioned concrete beam is modelled in finite element based software ANSYS. Concentric prestressing force is applied on two different shapes of plates. A case study is performed in which the loaded area ratio is varied. The results obtained are compared in terms of transverse tensile stress, longitudinal tensile stress and bursting force for both circular and rectangular shape plate. The calculated bursting tensile force is also compared from IS 1343:2012.
\end{abstract}

Keywords

Post-tensioned Beam, Anchorage Zone, Concentric Pre-stressing, Transverse Tensile Stress, ANSYS

\section{Introduction}

It is well establish fact that the basic economy of prestressed concrete lies in its high strength to weight and cost ratio, its resistance to fire and corrosion and its versatility and adaptability. In prestressed concrete members, stresses are induced during the construction in such a way that they can resist stresses caused by external applied loads. Prestressed structural member are widely used to achieve high strength at lower self-weight. Prestresed concrete is most suitable for long span structural element like beam and girder.

Broadly there are two methods of prestressing namely Pre-tensioning and Post-tensioning. In pre-tensioning, the prestressing tendons are tensioned before the concrete is placed while in Post-tensioning hardened concrete is stressed by applying external loads. In Post tensioned concrete beams, a duct is formed inside the beam and prestressing cable is kept inside the duct. Once the concrete gets harden, prestressing cable is stressed and anchored at the end of beam that reduced internal stresses in the concrete beam. Post tensioning application include office and apartments building, parking structure, slab-on-ground, bridges, sport stadium, rock and soil.

The anchorage zone is defined as the end portion of prestressed post-tensioned concrete beam starting from the loaded face to the section at a distance of $\mathrm{d}$ (depth of the beam) measured along the axis of the beam.

Longitudinal crack in an anchorage zone are resulted from transverse tensile stress produced by prestressing force. In pre-tensioning and post-tensioning, the longitudinal cracks observe in bursting zone along the axis of prestressing force short distance from girder. The control of anchorage zone cracking in prestressed concrete, the transverse reinforcement has been used to restrain the development of spalling crack and postpone the formation of bursting crack.

In IS 1343:2012 only formula is given to calculate bursting tensile force with rectangular prestressing plate. Hence there is much of space to work upon to study the bursting force and tensile stress distribution in end block of post tensioned members.

D. J. Douglas [1] has described the theoretical and experimental work on the stress concentration in anchorage zone. Both analytical and theoretical models were made and a method is given to solve 3-dimensional problem of anchorage zone mathematically. The results are compared with the available literature of other authors. K.T.Sundara Raja [2] has worked on the two dimensional theory of anchorage zone stresses in post-tensioned concrete beam. For analysing the results he compares his results with the results of Guyan,Morsch and sievers.He studied stress concentration in the two dimensional post-tensioned concrete block subjected to prestressed force. Pijush Kanti [3] investigated the transverses zone stresses in three axial direction of end block of prestressed concrete beam. The three cases were taken for the study namely central axial prestressing force with single cable, central axial prestressing force with multiple cable arrangement and axial prestressing force with eccentric cable. Stress distribution for multiple and eccentric anchorage on rectangular I section has been studied by A.LYetram [4].He studied bursting and spalling zone. R. C. Fenwick [5] performs the analytical and experimental work on the post-tensioned concrete beam. He did eighteen number of simple anchorage zone test using finite element method and also experimentally to study the bursting force after the crack is formed. He found that the value of bursting force used for designing of end block shows much of variance after once a primary crack forms in that region. Khapre and Gupta [06] made efforts to reduce the Computational time in the Finite Element Analysis by applying Parallel Computing Technique on Supercomputer PARAM 10000. The problem of Anchorage Zone in Prestressed Post-Tensioned Concrete Beam is investigated using this computer code. 
Gupta and Khapre [07] presented the analysis of the Anchorage Zone using Finite Element Method considering the problem as 2-Dimensional Plane Stress. They studied the effect of Poisson's Ratio over the stresses caused by prestressing force (Pk) in the Anchorage Zone. Brian Adjetey Boye (8) studied 2-dimensional finite element analysis on precast tunnel segments and developed an equation to calculate the bursting force in anchorage zone. 3-Dimwnsional finite element analysis was conducted on anchorage zone by Hyo-Gyoung Kwak [9].He calculated bursting force and did parametric study by varying various parameters. Study has given design method for post tensioned anchorage zone.

\section{Methodology}

In this paper the problem statement is idealized as 3 dimensional post-tensioned concrete end block. Cubical block with side'd' is adopted for this analysis. Default material properties of concrete available in ANSYS are used in the present analysis. To get accurate results, the mesh is kept advance fine with relevance centre. Here only the end block is modelled with the length of beam as equal to the depth of beam. Finite element based

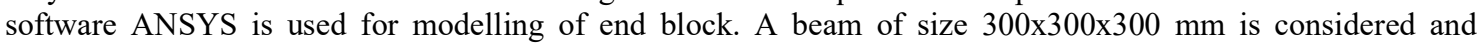
modelled. Displacement support is provided at the back face of loaded face such that displacement along the axis of loading is restricted. To check the results of present investigation the result obtained is compared with the results of available literature.

The results are checked in terms of transverse tensile stress, longitudinal tensile stress and bursting force occurs in anchorage zone. In order to validate the results comparison is done for different values of Bearing Ratios ( $\mathrm{k}=0.1$ to 0.5 for concentric loading). Once stresses are computed the bursting tensile force is calculated and compared with the magnitude obtained from IS1343:2012[8].

For present paper two cases are considered I) Concentric prestressing with circular anchorage plate and II) Concentric prestressing with rectangular anchorage plate.

\section{Case 1: Circular Shape Anchorage Plate}

The diameter of circular plate is adjusted such that value of $k$ (Ratio of loaded are to dispersion area) varies from 0.1 to 0.5 for concentric loading (see Fig. 1)

\section{Case 2: Rectangular Shape Anchorage Plate}

The area of prestressing force is adjusted such that the value of $\mathrm{k}$ (Ratio of loaded are to dispersion area) varies from 0.1 to 0.5 . (See.fig.2)

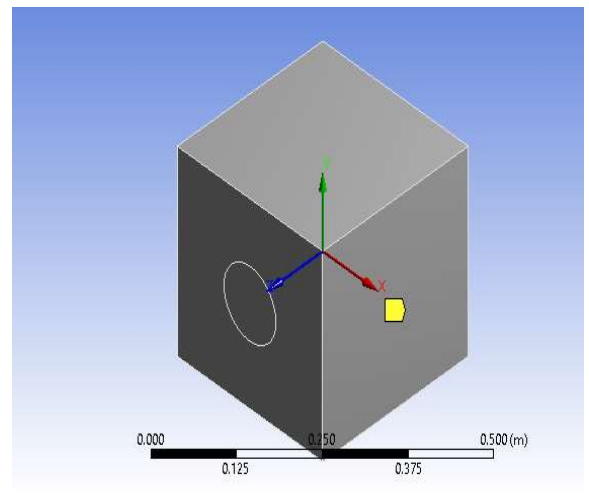

Fig.1: Ansys Model Showing Prestressing Circular Plate for Distribution Ratio $k=0.1$

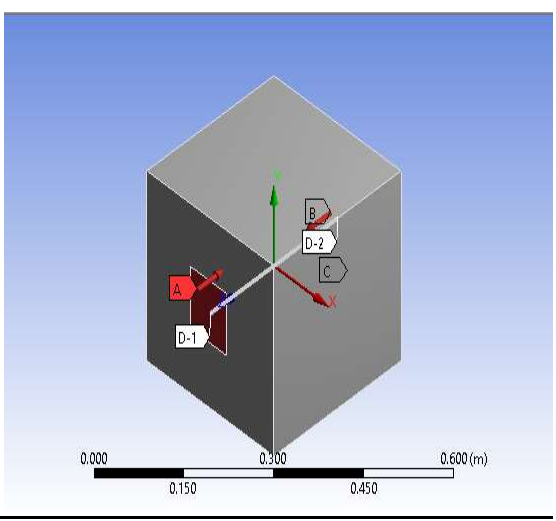

Fig.2: Ansys Model Showing Prestressing rectangular Plate for Distribution Ratio $\mathrm{k}=\mathbf{0 . 1}$

\section{Results and Discussion}

The investigation is done on anchorage zone with circular and rectangular prestressing plate and the stresses are calculated along the given path. The corresponding results are shown below for both the conditions. 


\section{A) Transverse Tensile Stress}

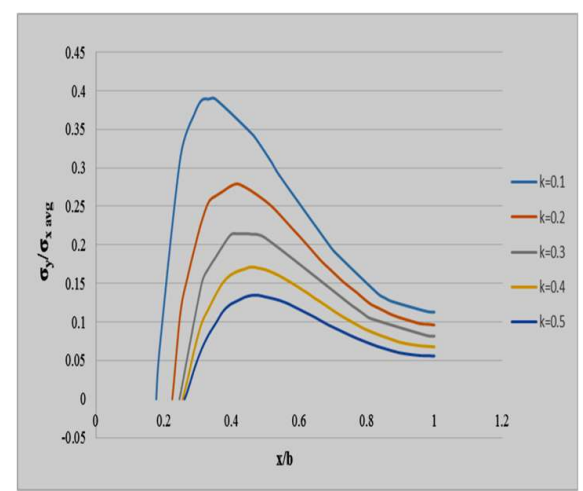

Fig. 3: Comparison of Transverse Tensile Stress along the Loaded Face (Circular Plate)

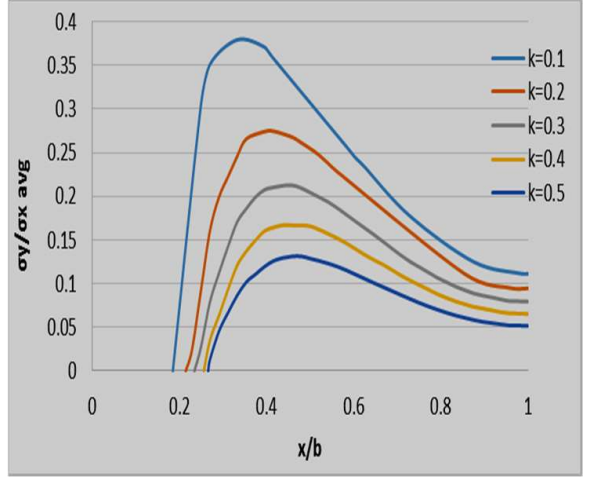

Fig.4: Comparison of Transverse Tensile Stress along the Loaded Face (Rectangular Plate)

Fig.3. shows comparison of transverse tensile stress along the loaded face for various values of $\mathrm{k}$ i.e. $\mathrm{k}=0.1$ to 0.5 .The graph shows that as the value of ' $\mathrm{k}$ ' increases the peak bursting stress reduces from $\mathrm{k}=0.1$ to 0.5 . Also it is clear from graph that as the value of area ratio increases the location of zero stress moves away from the centre of horizontal axis. This clears that more the value of loaded area lesser will be the peak of the transverse tensile stress.

Fig.4.shows the transverse tensile stress along the loaded face in rectangular prestressing force .It is having the maximum peak of 0.38 for area ratio of 0.1 and minimum peak of 0.131 for $\mathrm{k}=0.5$. As the ratio of loaded area to loaded geometry increases the peak of transverse stress reduces. Also the position of zero stress value moves away from centre.

\section{b) Longitudinal Tensile Stress}

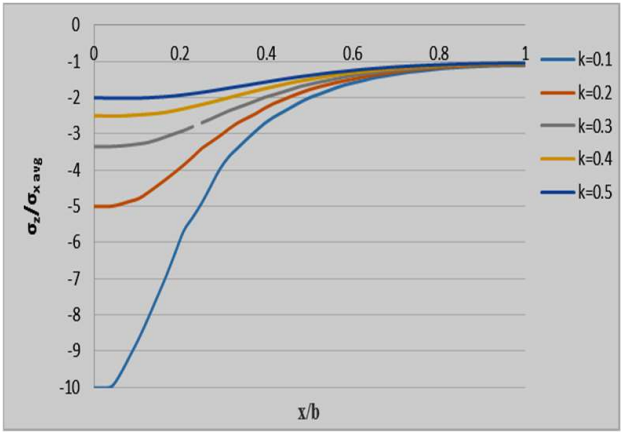

Fig.5: Comparison of Longitudinal Tensile Stress along the Axis of Loading

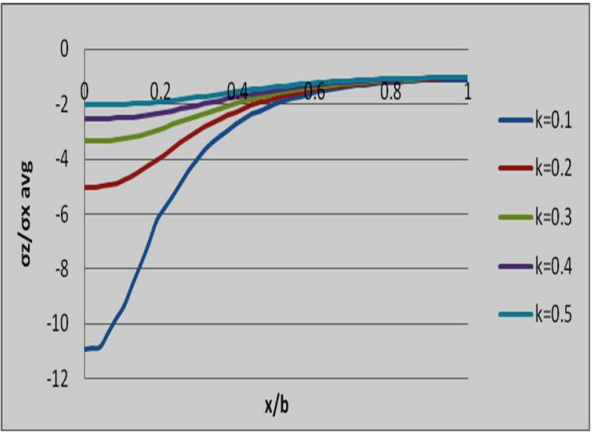

Fig.6: Longitudinal Tensile Stress along the Axis of Loading Different Bearing Ratios

Fig. 5 shows the comparison of longitudinal stress along the loaded face of given geometry. It is clear from graph as the value of area ratio increases the stress in compression also reduces. The percentage reduction in longitudinal stress reduces from $\mathrm{k}=0.5$ to 0.1 i.e. it is maximum between 0.5 to 0.4 and minimum for 0.2 to 0.1

Fig. 6 shows the longitudinal tensile stress along the loaded face. From graph it is clear that the as the area ratio increases the stress along axis of loading also reduces. More the $\mathrm{k}$ value lesser will be the stress concentration along axis of loading. 
c) Bursting Tensile Force

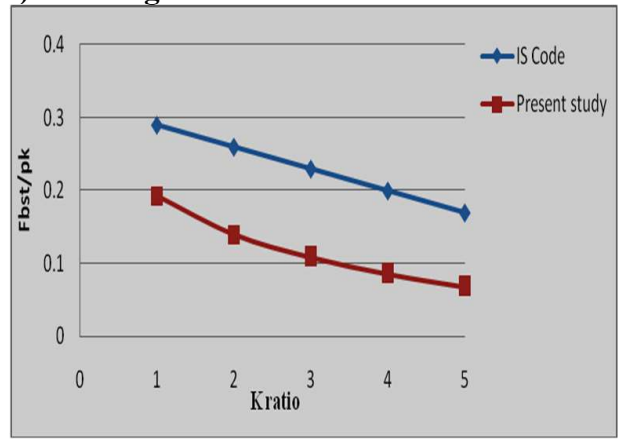

Fig.7: Comparison of Bursting Tensile

Force along the Transverse Direction (Circular Plate)

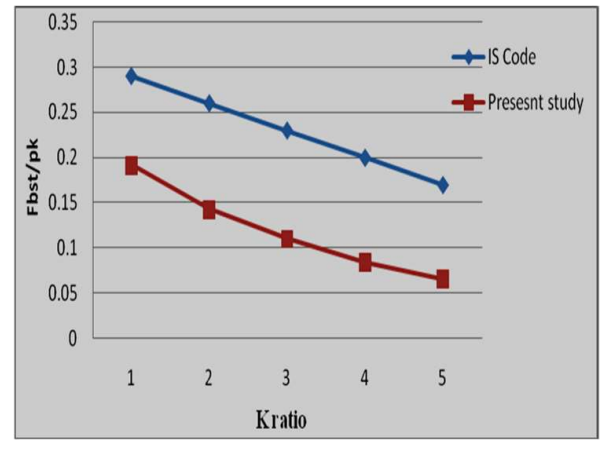

Fig.8: Comparison of Bursting Tensile Force along the Transverse Direction (Rectangular Plate)

Fig.7 \& Fig.8 above shows the comparison of bursting tensile stress As per Indian standard code 1343:2012 and as per the present study. From graph it is clear that there is huge difference between the bursting forces given by IS code and the present study for both circular as well as rectangular prestressing force. The IS code has given the formula which is on very much conservative side. The bursting force given by IS code is much higher as one given by this study. The percentage gap between the forces increase from $\mathrm{k}=0.1$ to 0.5 i.e. it is minimum for 0.1 and maximum for 0.5 .

d) Comparison of Results

\begin{tabular}{|c|c|c|c|c|c|c|c|c|c|c|}
\hline $\mathrm{SN}$ & $\begin{array}{c}\mathrm{k} \\
\text { Ratio }\end{array}$ & \multirow{6}{*}{ Circle } & $\begin{array}{c}\text { Max } \\
\text { transverse } \\
\text { stress }\end{array}$ & $\begin{array}{c}\text { Location } \\
\text { of Zero } \\
\text { stress }\end{array}$ & Fbst & \multirow{6}{*}{ Square } & $\begin{array}{c}\text { Max } \\
\text { transverse } \\
\text { stress }\end{array}$ & $\begin{array}{c}\text { Loct. of } \\
\text { Zero } \\
\text { stress }\end{array}$ & Fbst & $\begin{array}{c}\text { Fbst } \\
\text { From } \\
\text { IS } \\
\text { code }\end{array}$ \\
\hline 1 & $\mathrm{k}=0.1$ & & 0.389 & 0.178 & 0.193 & & 0.379 & 0.185 & 0.1918 & 0.29 \\
\hline 2 & $\mathrm{k}=0.2$ & & 0.275 & 0.2256 & 0.1395 & & 0.274 & 0.215 & 0.1425 & 0.26 \\
\hline 3 & $\mathrm{k}=0.3$ & & 0.214 & 0.246 & 0.1084 & & 0.212 & 0.235 & 0.1095 & 0.23 \\
\hline 4 & $\mathrm{k}=0.4$ & & 0.168 & 0.256 & 0.0852 & & 0.164 & 0.256 & 0.0839 & 0.20 \\
\hline 5 & $\mathrm{k}=0.5$ & & 0.134 & 0.262 & 0.0678 & & 0.131 & 0.266 & 0.0649 & 0.17 \\
\hline
\end{tabular}

Table 1: Comparison of Different Values of Circular and Rectangular Pre-stressing Plate

Table 1 shows the results of both circular and rectangular prestressing plate for varying area ratio $(\mathrm{k}=0.1$ to 0.5$)$ It shows the values of maximum transverse tensile stress, Location of zero stress and bursting tensile force. As the area ratio increases from 0.1 to 0.5 the maximum transverse tensile stress reduces up to 3times. The location of zero stress shifts away from origin as the area ratio increases. The magnitude of bursting tensile force reduces the size of plate increases. When we compare the results of circular and rectangular plate it is found that there is negligible change in the magnitude of stress and bursting force. Last column of table shows the bursting force calculate as per IS 1343. When this magnitude of bursting force is compared with the present study it shows huge difference between the magnitude. Hence IS code has given the busting tensile force formula which is on very much conservative side.

\section{Conclusion}

Based on computer simulation carried out on ANSYS on end block of post tensioned concrete beam, following conclusions are drawn.

1. From Case 1 and case 2 i.e. Geometry with circular shape and rectangular shape anchorage plate it is clear that there are very fine changes and differences between the results of circular and rectangular plate. Hence shape of anchorage plate does not influence the maximum tensile stress and the bursting tensile force of end block very much.

2. As the value of area ratio $(\mathrm{k})$ increases the transverse tensile stress along the loaded face decreases from 0.1 to 0.5 also the position of zero stress shifted away from centre both the cases.

3. For longitudinal tensile stress as the value of area ratio $(\mathrm{k})$ increases the stress along the longitudinal axis also increases for both circular and rectangular prestressing force. 
4. Study shows that as the value of area ratio increases the bursting force reduces. Also the bursting force calculated from present study gives very much less magnitude of bursting force when compared with the IS code values.

5. Results indicates that the cross section of prestressing plate does not influence the maximum transverse tensile stress, location of zero stress and also the bursting tensile force in anchorage zone.

\section{References}

1. D. J. Douglas, and N. S. Trahair, "An examination of the stresses in the anchorage zone of a posttensioned prestressed concrete beam", Magazine of Concrete Research, Vol. 12, No. 34, (1960).

2. K.T.Sundara raja Iyenger, "Two dimensional theories of anchorage zone stresses in post tensioned prestressed beams", American Concrete Institute, Journal Proceedings, Vol.59, Issue 10, pp1443-1456, (1962).

3. Pijush kanti som and Kalyanmay ghosh, "Anchor zone stresses in prestressed concrete beams "Proceedings of American society of Civil engineers', Vol.90.No.ST4, (1965).

4. A. L. Yettram and K. Robbins," Anchorage zone stresses in post-tensioned uniform members with eccentric and multiple anchorages", Magazine of Concrete Research: Vol. 22, No. 73,(1970).

5. R. C. Fenwick and S. C. Lee, "Anchorage zones in prestressed concrete members", Magazine of concrete research,vol.38(135),pp77-89,(1986)

6. Gupta, P. K. and Khapre, R.N. and Sinhal, A.A.,"Analysis of Spalling Zone In Prestressed PostTensioned Concrete Beam Using Supercomputer Param 10000”, National Conference on Structural Engineering and Mechanics, BITS, Pilani, 2004.

7. Gupta, P. K. and Khapre, R.N., “ A study on development of stresses in anchorage zone using parallel processing Asian journal of civil engineering (building and housing), Vol. 9, NO. 1,Pp 47-59(2008)

8. Brian Adjetey Boye, Samuel Jonah Abbey, Samson Ngambi, Joao Fonte,” Development of Improved Models for Estimation of Bursting Stresses in Elements under High-Concentrated Load "Latin American journal of solid and structures, 16(1) e156,(2018).

9. Hyo-Gyoung Kwak, Joung Rae Kim and Minsuk Shim," Investigation of Bursting Forces in Post Tensioned Anchorage Zone", Advances in structural engineering and mechanics, Korea (2017).

10. IS 1343:2012," Indian Standard, Prestressed concrete — code of Practice (second revision)", (2012). 